\title{
PENGOLAHAN DAUR ULANG MINYAK BEKAS MENJADI BIODISEL UNTUK SUMBER ENERGI ALTERNATIF DI KELURAHAN KARYA MERDEKA KABUPATEN KUTAI KERTANEGARA
}

\author{
Andi Sri Irtawaty', Maria Ulfah ${ }^{2}$, Armin $^{3}$ \\ ${ }^{1,2,3}$ Politeknik Negeri Balikpapan
}

andi.sri@poltekba.ac.id, maria.ulfah@poltekba.ac.id, armin@poltekba.ac.id

\begin{abstract}
Abstrak
Abstrak Biodiesel adalah salah satu bahan bakar alternatif yang ramah lingkungan, tidak mempunyai efek terhadap kesehatan yang dapat dipakai sebagai bahan bakar kendaraan bermotor yang dapat menurunkan emisi bila dibandingkan dengan minyak diesel. Biodisel dapat diperoleh dari hasil daur ulang minyak jelantah yang dicampurkan dengan zat kimia berupa methanol dan $\mathrm{NaOH}$ dengan perbandingan (1: $0.5: 0.001)$. Implementasi biodiesel dapat menggantikan fungsi solar pada mesin genset ataupun mesin dompeng. Kegiatan PkM tahun 2020 dilaksanakan di Kelurahan Karya Merdeka, Kabupaten Kutai Kertanegara. Hampir 27\% penduduknya memiliki mata pencaharian sebagai petani perkebunan sawit. Pelaksanaan PkM berlangsung selama 3 hari yang dihadiri 25 petani perkebunan sawit. Manfaat kegiatan ini adalah mitra mampu mendaur ulang dan mengimplementasikan biodiesel yang 3 kali lebih irit dari solar sebagai bahan bakar mesin dompeng (mesin air yang digunakan untuk mengairi perkebunan sawit mereka). Tujuannya yaitu menghemat energy, yaitu 3 liter solar dapat diganti dengan 1 liter biodiesel. Telah dibuktikan biodiesel lebih hemat 3 kali lipat dari solar (3 jam : 1 jam) dengan ukuran yang sama.
\end{abstract}

Kata Kunci : biodiesel, minyak jelantah, methanol, $\mathrm{NaOH}$, solar

\section{PENDAHULUAN}

Listrik merupakan salah satu kebutuhan pokok manusia. Kebutuhan akan energi listrik semakin besar seiring dengan pertambahan penduduk dan meningkatnya aktifitas masyarakat. Pertambahan ini harus diimbangi dengan penambahan sumber-sumber energi baru, karena jumlah energi listrik yang disediakan terbatas dan penggunaan kebutuhan yang sangat berlebih, selain itu juga dikarenakan PT. PLN sebagai penyedia energi listrik sangat bergantung pada bahan bakar minyak, maka tidak heran jika harga energi listrik tersebut semakin melambung tinggi (hutagulung 2017).
Berdasarkan hasil survey, tim PkM Jurusan Teknik Elektro Politeknik Negeri Balikpapan memilih Kelurahan Karya Merdeka, Kabupaten Kutai Kertanegara sebagai lokasi kegiatan PkM dengan alasan karena daerah tersebut terkenal dengan kelapa sawitnya. Sekitar $27 \%$ penduduknya berprofesi sebagai buruh tani perkebunan sawit, sehingga tingkat perekonomian masyarakatnya masih ada yang tergolong miskin. Perlu diketahui bahwa dari segi kesehatan, minyak goreng bekas sudah tidak layak lagi digunakan. Namun minyak tersebut dapat didaur ulang menjadi sumber energy listrik alternative berupa biodiesel. Dari hasil penelitian sebelumnya (AS. Irtawaty, 
2018) telah berhasil mengujicobakan biodisel pada mesin dompeng di perkebunan sawit RT.02 (gambar 1).

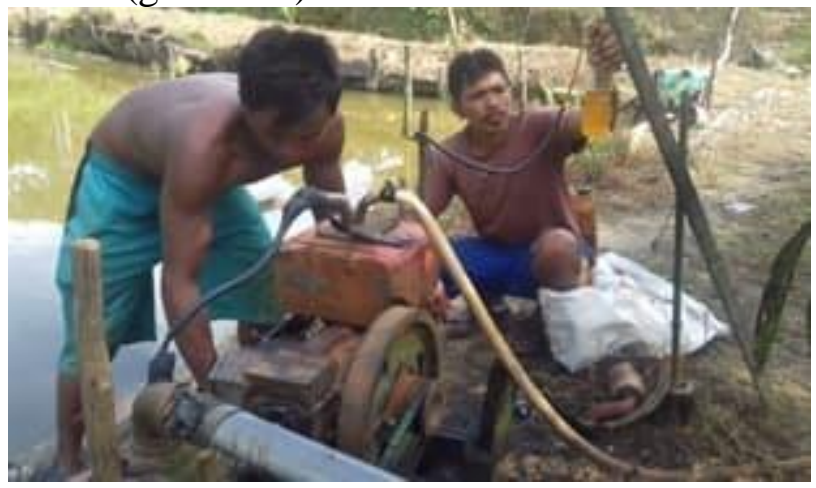

Gambar 1. Hasil uji coba biodiesel pada mesin dompeng di perkebunan sawit RT.02 Kelurahan Sungai Merdeka

Tujuan akhir yang dicapai dari kegiatan PkM ini adalah, meningkatkan taraf kesejahteraan hidup petani, yang sebelumnya menggunakan 1 liter solar selama 1 jam, menjadi 1 liter biodiesel selama 3 jam. Berarti penghematan 3 kali lipat.

\section{METODE}

Metode pelaksanaan kegiatan PkM berupa pelatihan dan praktek langsung bagi masing-masing peserta PkM didampingi oleh tim pelaksana PkM. Adapun tahapan kegiatan PkM meliputi :

1) Tahapan $1:$ Mengidentifikasi kebutuhan masyarakat.

2) Tahapan 2 : Merancang sebuah konsep teknologi sederhana sebagai bentuk kontribusi kepada mitra. Berikut diagram alir (flowchart) pelaksanaan kegiatan pelatihan pembuatan biodiesel disajikan pada gambar 2 .

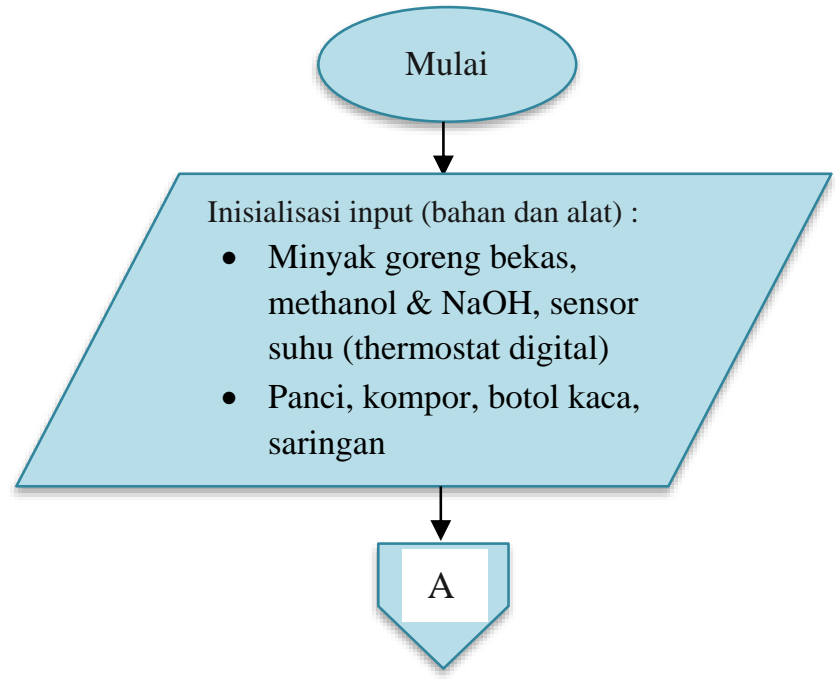

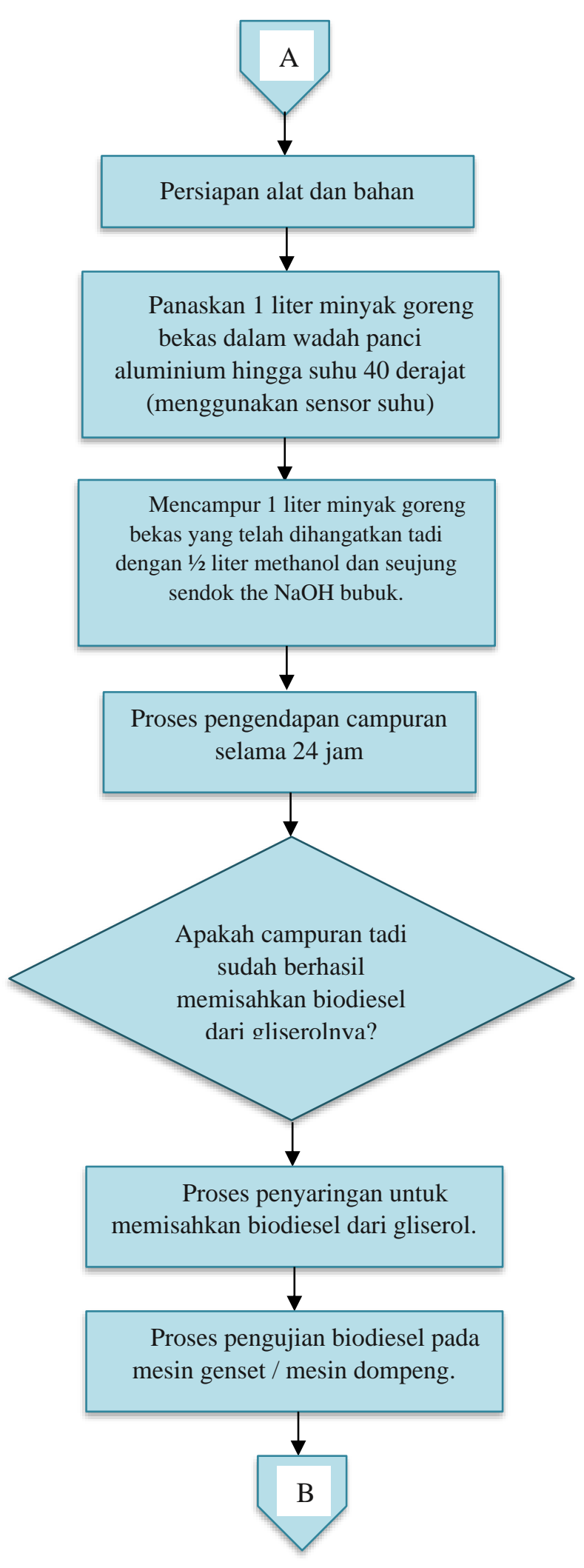

Teknologi Tepat Guna 


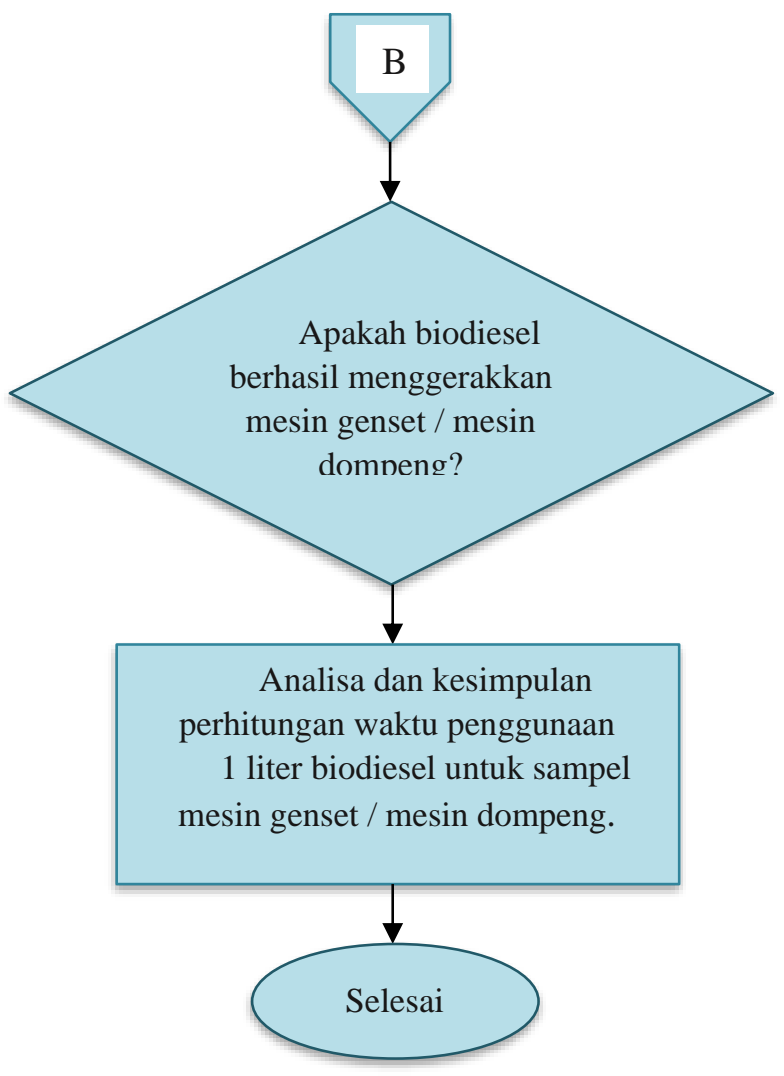

Gambar 2. Flowchart pelaksanaan kegiatan PkM

3) Tahapan $3:$ Membuat teknologi sederhana yang memudahkan mitra dalam pembuatan biodiesel.

4) Tahapan 4 : Pengujian output dilakukan dengan mengimplementasikan biodiesel sebagai bahan bakar penggerak genset dan mesin dompeng.

5) Tahapan 5: Pendampingan operasional, dimana tim pelaksana mendampingi mitra saat proses pengujian biodiesel pada mesin dompeng. Untuk menghindari kesalahan teknis, pengujian dilakukan secara tutorial dari tim pelaksana, mulai dari takaran biodiesel hingga mengukur waktu penggunaan 1 liter biodiesel dapat digunakan berapa jam pada genset atau mesin dompeng.

6) Tahapan 6 : Diseminasi teknologi kepada masyarakat / mitra. Dalam hal ini, tujuan capaian yang diinginkan tim pelaksana adalah mitra memiliki keterampilan yang cukup untuk membuat biodiesel secara mandiri sehingga dapat memenuhi kebutuhan listrik alternative selain bergantung dari kontribusi listrik PLN.

7) Tahapan 7 : Evaluasi pelaksanaan program dan keberlanjutan program di lapangan. Untuk keberlanjutan program di lapangan, maka dilakukan monitoring secara berkala sekaligus tetap menjalin hubungan baik dengan mitra untuk rencana kegiatan pelatihan berikutnya dengan tema yang berbeda.

\section{HASIL DAN PEMBAHASAN}

Kegiatan Pengabdian kepada Masayarakat (PkM) Jurusan Teknik Elektronika dengan judul "Pengolahan Daur Ulang Minyak Bekas Menjadi Biodisel Untuk Sumber Energi Alternatif Di Kelurahan Karya Merdeka Kabupaten Kutai Kertanegara" dilaksanakan selama 3 hari yaitu 1 hari tatap muka (ceramah dan praktek langsung) dilaksanakan pada hari kamis tanggal 2 Juli 2019 bertempat di balai desa Kelurahan Karya Merdeka dan 2 hari daring online yaitu pada hari jumat tanggal 3 Juli 2020 dan hari senin tanggal 6 Juli 2020.

Adapun teknis pelaksanaan $\mathrm{PkM}$ dibagi menjadi beberapa tahapan yang akan diuraikan sebagai berikut :

\section{Registrasi Peserta Pelatihan}

Kegiatan PkM ini dihadiri oleh 25 peserta dari pihak mitra Kelurahan Karya Merdeka dan 5 orang tim $\mathrm{PkM}$ dari pihak penyelenggara, Politeknik Negeri Balikpapan. Di hari pertama, kamis tanggal 2 Juli 2020 diawali dengan registrasi peserta.

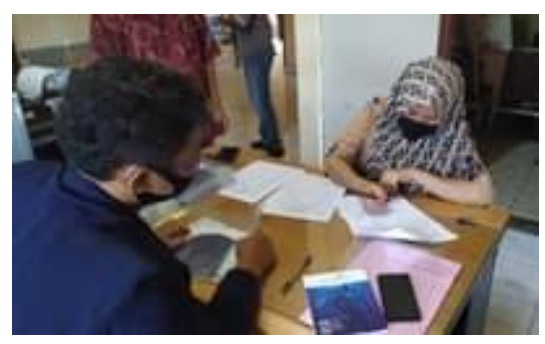

Gambar 3. Registrasi peserta

\section{Pembukaan kegiatan PkM}

Setelah registrasi selesai, dilanjutkan dengan Teknologi Tepat Guna 206 
pemberian kata sambutan oleh ketua tim pelaksana PkM yaitu Andi Sri Irtawaty yang dilanjutkan oleh kata sambutan perwakilan institusi Politeknik Negeri Balikpapan yang diwakili oleh Drs. Armin, M.T. Selanjutnya dari pihak mitra yang mewakili Lurah Karya Merdeka yaitu Bapak Hambali memberikan sambutan sekaligus membuka dengan resmi acara kegiatan PkM di Kelurahan Karya Merdeka yang akan berlangsung selama 3 hari sesuai berita acara dan undangan yang telah disampaikan kepada masing-masing peserta.

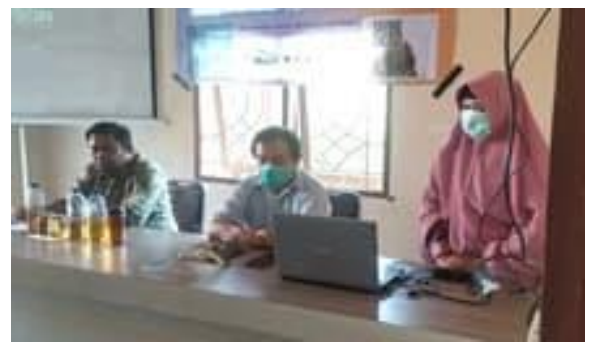

Gambar 4. Sambutan ketua panitia PkM

\section{Kegiatan Inti PkM}

Pelaksanaan kegiatan PkM dilaksanakan selama 3 hari yang terbagi menjadi 2 metode yaitu :

1. Hari pertama, kamis / 2 Juli 2020, menggunakan metode ceramah dan praktek langsung.

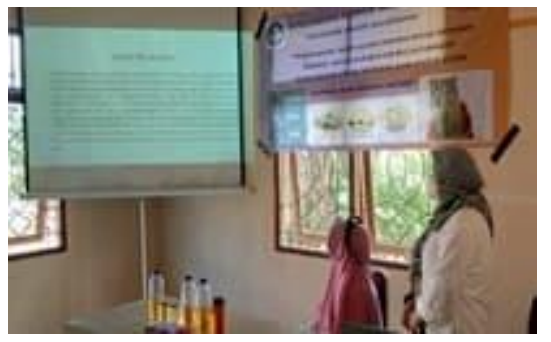

Gambar 5. Penyajian materi dasar tentang biodiesel

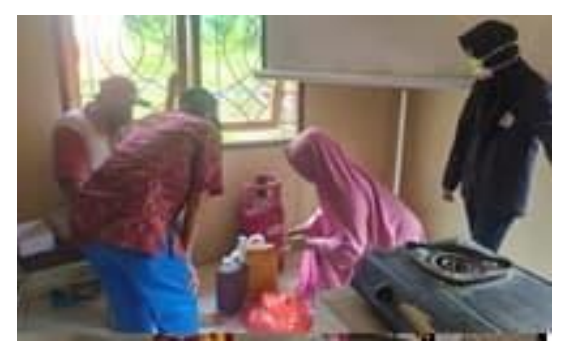

Gambar 6. Persiapan alat dan bahan

Alat-alat yang digunakan yaitu panci, sendok, kompor, thermostat digital, dan wadah penampung dari bahan kaca (toples kaca). Sedangkan bahan-bahan utama pembuatan biodiesel yaitu minyak jelantah, methanol, $\mathrm{NaOH}$ dan cuka makan.

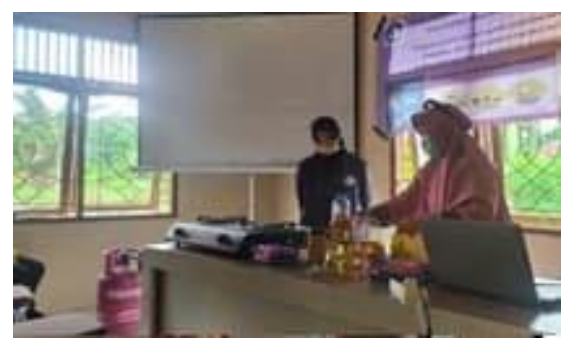

Gambar 7. Menakar bahan-bahan utama

Untuk mendapatkan hasil daur ulang yang maksimal, maka perlu diperhatikan takaran yang tepat terkait bahan-bahan utama pembuatan biodiesel, yaitu :

- 1 liter minyak jelantah.

- $1 / 3$ liter methanol.

- 0.1 mgram $\mathrm{NaOH}$.

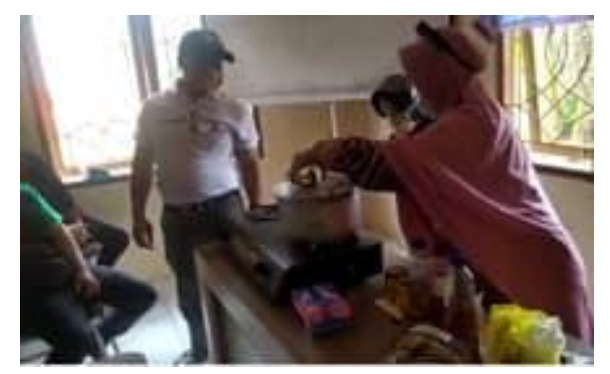

Gambar 8. Proses pembuatan biodiesel

Langkah awal yaitu memanaskan minyak jelantah dalam wadah panci stainlisteal diatas kompor hingga suhu minyak jelantah mencapai 40 derajat. Setelah itu, kompor dimatikan. Selanjutnya panci yang berisi minyak jelantah diletakkan di lantai atau dijauhkan dari kompor. Hal ini sangat penting untuk diingat karena bahan utama daur ulangnya adalah methanol yaitu sejenis bahan kimia yang mudah meledak jika berdekatan dengan api. Oleh karena itu, disarankan proses pencampuran minyak jelantah dilakukan di tempat yang aman (jauh dari kompor). Setelah semua bahan-bahan utama bercampur

$$
\text { Teknologi Tepat Guna }
$$


(minyak jelantah, methanol dan $\mathrm{NaOH}$ ), maka mulainya diaduk dengan sendok dari bahan stainlisteal selama 10 menit. Setelah seluruh bahan bercampur merata, lalu dituangkan ke dalam wadah lain yang terbuat dari kaca (toples kaca). Lalu disimpan pada tempat yang kering dan sejuk. Diamkan selama 24 jam.

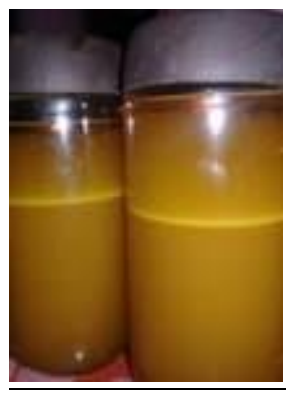

Gambar 9. Proses pengendapan selama 24 jam

Setelah 24 jam, maka biodiesel terbentuk seperti pada gambar 10 .

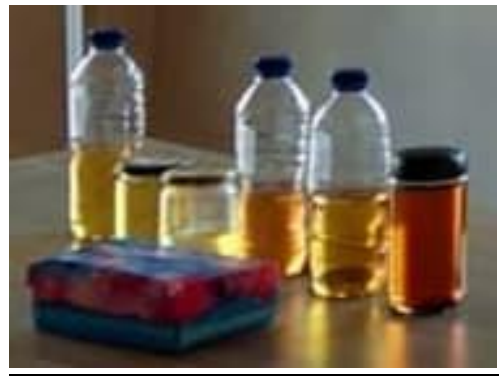

Gambar 10. Biodisel hasil daur ulang dari bahan minyak jelantah, methanol dan $\mathrm{NaOH}$

Biodisel yang terbentuk dapat digunakan untuk berbagai keperluan (sebagai sumber energy alternatif), seperti menggantikan fungsi solar dan sifatnya lebih hemat, yaitu dapat menggerakkan mesin dompeng yang digunakan oleh petani perkebunan sawit dan juga dapat menggerakkan mesin genset bermesin diesel. Fungsi lain biodiesel juga dapat menyalakan ublik (lampu tradisional berbahan bakar minyak gas) dan dapat digunakan untuk membakar sampah. Di hari pertama kegiatan $\mathrm{PkM}$, pengujian fungsi biodiesel dilakukan di halaman balai desa Kelurahan Karya Merdeka, yaitu dengan membakar sampah. Hasilnya seperti disajikan pada gambar 11.

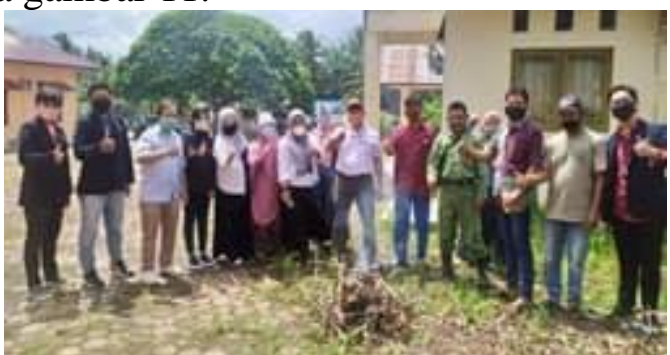

Gambar 11. Pengujian biodiesel berupa pembakaran sampah di halaman Kantor Kelurahan Karya Merdeka

2. Hari kedua, jumat / 3 Juli 2020, menggunakan metode daring online via google meet.
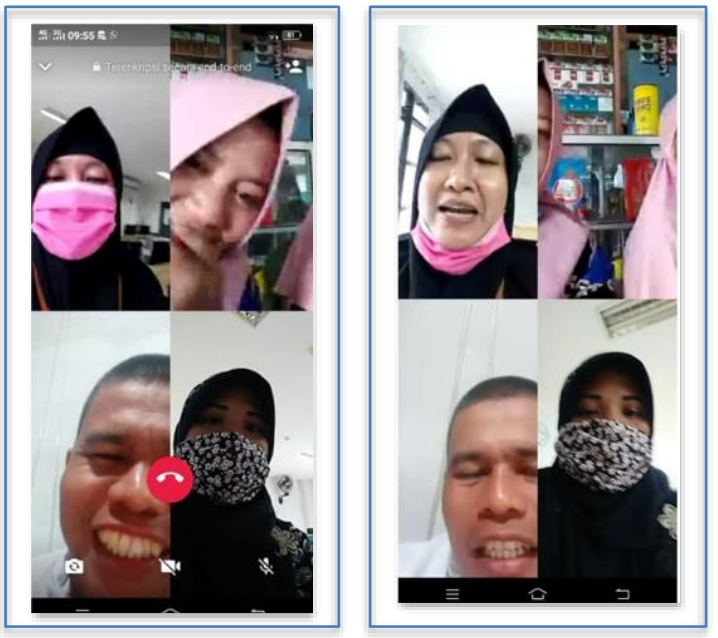

Gambar 12. Kegiatan PkM di hari kedua, dilaksanakan secara daring via google meet

Biodisel merupakan sumber energy alternatif yang diperoleh dari hasil daur ulang minyak jelantah dengan bahan campuran utama yaitu methanol, $\mathrm{NaOH}$ dan cuka makan. Biodisel memiliki fungsi yang sama dengan solar. Namun keunggulan biodiesel lebih hemat 3 kali lipat dari solar. Uraian lengkapnya disajikan pada tabel 1 . 
Tabel 1. Perbandingan lama penggunaan antara solar dan biodiesel pada mesin dompeng

\begin{tabular}{cccc}
\hline $\begin{array}{c}\text { Bahan } \\
\text { bakar }\end{array}$ & Takaran & $\begin{array}{c}\text { Lama } \\
\text { penggunaan }\end{array}$ & Keterangan \\
\hline Solar & 1 liter & 2 jam & $\begin{array}{c}\text { Untuk } \\
\text { pengujian } \\
\text { pada mesin } \\
\text { dompeng }\end{array}$ \\
\hline
\end{tabular}

Terlihat nyata keunggulan biodiesel jauh lebih irit dan ramah lingkungan. Perbandingan penggunaannya antara solar : biodiesel $=2$ jam $: 6$ jam $=1: 3$. Artinya biodiesel lebih hemat 3 kali lipat daripada solar.

3. Hari ketiga, senin / 6 Juli 2020, menggunakan metode daring online via google meet.

Kegiatan PkM di hari ketiga yang dilaksanakan pada hari senin / 6 Juli 2020 secara daring online via google meet merupakan kegiatan tambahan sekaligus penutupan. Tim pelaksana PkM menyajikan pengetahuan tambahan kepada peserta berupa cara membuat handityzer sendiri dengan bahan-bahan yang mudah kita dapatkan. Bahan utama pembuatan handnityzer yaitu ; alcohol 70\%, aloe vera (sari lidah buaya), bibit parfum dan wadah botol plastik. Perbandingannya alcohol : aloe vera : parfum $=1: 1 / 3: 1 / 20=$ handnityzer.

Pada hari ketiga, penutupan PkM dilakukan oleh ketua panitia sekaligus merangkum seluruh hasil kegiatan PkM.

Biodiesel memiliki keunggulan lebih daripada solar, yaitu lebih irit dan ramah lingkungan. Jika 1 liter biodisel dapat digunakan selama 6 jam untuk menggerakkan mesin dompeng petani perkebunan sawit, maka 1 liter solar hanya mampu menggerakkan mesin dompeng selama 2 jam. Dari segi biaya bahan-bahannya. Minyak jelantah bisa diperoleh secara gratis di rumah-rumah makan atau di restauran yang sudah dianggap limbah dan akan dibuang oleh pemilik restaurant. Sementara 1 liter methanol seharga $\mathrm{Rp}$ 20000,-, dapat digunakan untuk mendaur ulang 3 liter minyak jelantah, ditambahkan 0.3 mgram $\mathrm{NaOH}$ (seharga Rp 15,-). Hasilnya akan diperoleh 4 liter biodiesel hanya membutuhkan biaya Rp 20015,-. Sedangkan 4 liter solar seharga Rp 6.000,- x $4=$ Rp 24000,-. Lebih irit dan lebih ramah lingkungan. Untuk lama penggunaannya, 4 liter solar dapat digunakan selama $4 \times 2$ jam $=8$ jam. Sedangkan 4 liter biodiesel dapat digunakan selama $4 \times 6$ jam $=24$ jam. Berarti perbandingan hematnya biodiesel dibandingkan dengan solar yaitu 3 kali lipatnya.

Kepuasan mitra terukur melalui pengisian kuisioner online pada URL : https://bit.ly/2BQG13f. Kesan-kesan peserta / mitra kegiatan PkM yaitu mendapatkan tambahan pengetahuan yang menurut mereka akan menjadi nilai lebih dalam meningkatkan kesejahteraan perekonomian keluarga, terutama beberapa peserta memohon kepada pihak Kelurahan Karya Merdeka agar memfasilitasi aspirasi dan ide mereka untuk meminta bantuan pemerintah kota agar kegiatan PkM tersebut dapat dikembangkan untuk kemajuan pengetahuan bagi generasi putraputri mereka di masa mendatang.

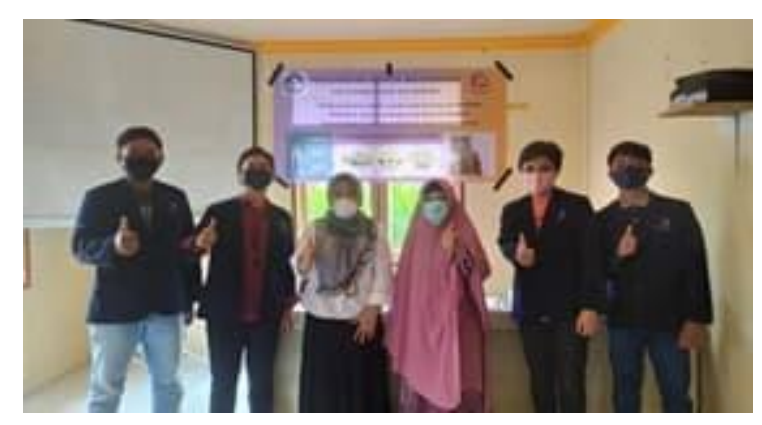

Gambar 13. Tim PkM DIPA Poltekba 2020

\section{KESIMPULAN}

Biodiesel merupakan sumber energy alternatif yang ramah lingkungan dan dapat menggantikan fungsi solar serta jauh lebih irit daripada solar. Biodisel dapat diperoleh dari proses daur ulang minyak jelantah yang dicampurkan dengan methanol dan $\mathrm{NaOH}$. Untuk mendaur ulang 1 liter minyak jelantah, dibutuhkan 1/3 liter methanol dan 0.1 mgram NaoH. Setelah diaduk merata dan didiamkan selama 24 jam, maka diperoleh 1 liter biodiesel. Keunggulannya

$$
\text { Teknologi Tepat Guna }
$$


dibandingkan dengan solar yaitu 1 liter solar dapat menggerakkan mesin dompeng selama 2 jam, sedangkan 1 liter biodiesel dapat menggerakkan mesin dompeng selama 6 jam. Berarti biodiesel lebih irit 3 kali lipat daripada solar. Kegiatan PkM ini dihadiri oleh 25 peserta dari pihak mitra dan 5 orang tim pelaksana PkM. Dari hasil kuisioner terlihat antusias warga dalam memberikan saran dan pendapatnya. Rata-rata mereka merasa puas dan berusaha mempraktekkan serta mengimplementasikan biodiesel sebagai sumber energy alternatif. Terutama untuk menggerakkan mesin dompeng dan menyalakan lampu tradisional (ublik).

\section{UCAPAN TERIMAKASIH (Bila ada)}

Ucapan terimakasih disampaikan kepada P3M Poltekba yang telah memberikan kontribusi dalam pelaksanaan kegiatan $\mathrm{PkM}$ ini, juga terima kasih kepada pihak mitra Kelurahan Karya Merdeka yang telah memfasilitasi sarana tempat kegiatan pelaksanaan PkM di Balai Desa Kelurahan Karya Merdeka, dan kepada seluruh pihak-pihak yang turut mendukung terselenggaranya kegiatan PkM tersebut.

\section{REFERENSI}

Hutagulung, S. N. (2017). PROTYPE RANGKAIAN INVERTER DC KE AC
900 WATT. Jurnal Pelita Informatika, 16(3), 278-280.

Irtawaty, A. S. (2018). RANCANG BANGUN SISTEM DAUR ULANG MINYAK GORENG BEKAS BERBASIS ALGORITMA FUZZY LOGIC. Jurnal Simetris, 9(2).

Mahlinda. (2011). PROSES PEMURNIAN METANOL HASIL SINTESA BIODIESEL MENGGUNAKAN ROTARY EVAPORATOR. JURNAL HPI, 24(1), 20-26.

Risnoyatiningsih, S. (2010, September). BIODIESEL FROM AVOCADO SEEDS BY TRANSESTERIFICATION PROCESS. Jurnal Teknik Kimia, 5(1), 345.

Yandri, V. (2012). PEMANFAATAN MINYAK JELANTAH SEBAGAI BIODIESEL UNTUK BAHAN BAKAR BUS KAMPUS UNAND DI PADANG. Jurnal Aplikasi Ipteks untuk Masyarakat, 1(2), 119-125. Retrieved from http://jurnal.unpad.ac.id/dharmakarya/articl e/download/8205/3754 